\title{
POSTNECROTIC PANCREATIC PSEUDOCYST COMPICATED WITH GASTRIC PENETRATION AND BLEEDING
}

\author{
Plachkov I., Pl. Chernopolsky, V. Bozhkov, Pl. Arnaudov \\ Second department of surgery - MHAT "Sv. Marina", Medical university - Varna
}

Reviewed by: assoc. prof. R. Radev

\section{RESUME}

The pancreatics pseudocysts, complicated with haemorhage are serious complication of the acute and chronic pancreatitis, which can lead to massive gastrointestinal bleeding and are associated with high mortaliy. We are presenting a clinical case of 52 years old patient with pancreatic pseudocyst, manifested by massive haemorhage and haematemesis after spontaneous posterior wall, gastric penetration. The treatment must be conducted in highly specialized and with highly equipped medical centers. The approach and the surgical treatment should be defined by the patients condition and the intraopperative findings.

Key words: complicated pancreatic pseudocyst, gastrointestinal bleeding

\section{INTRODUCTION}

The pancreatic pseudo cysts are common complication of othe acute and chronic pancreatitis. By infiltration of the peripancreatic tissues and organs they could lead to severe complications. Serious complication of the penetrating pancreatic pseudo cysts is massive gastrointestinal bleeding, which correlates with high rate of mortality.

\section{CASE REPORT}

We present a case of a 50 year old woman with pancreatic pseudo cyst, manifested by massive haematemesis after posterior gastric wall rupture. The patient was admitted in a surgical department and was investigated with physical exams, laboratory tests, abdominal ultrasound scan and CT scan. The results from the exam show an anemic syndrome ( $\mathrm{Hb} 51 \mathrm{~g} / \mathrm{l}$, Ht 0,18 Leuc 11,6) and hypoproteinaemia (TPr-44); Ultrasound and CT-scan data of pseudo cystic pancreatic tale formation; endoscopic evidence of major bleeding "ulcer" of the posterior gastric wall - maintained endoscopic haemostasis, after which was determined white like liquid drainage from the ulcer recess.

We start intensive pre operative treatment: correction of the anemic syndrome and the hypoproteinemia, and medication of the cardiologic pathology.

Fourteen hours after the hospitalization, the patient vomits abundant quantity of blood and was operated with the clinical expression of hemorrhagic shock. Throughout lig.

Address for correspondence:

I. Plachkov, Second dept. of surgery, MHAT "Sv. Marina", Medical university - Varna BG-9002 Varna, 1, Hristo Smirnenski Str.

e-mail: iplachkov@mail.bg gastrocolicum was found $/ 8 \times 10 \mathrm{~cm} /$ pancreatic pseudo cyst, containing fetid necrotic pancreatic tissues and gore. After removing the necrotic tissues we discover lineal artery ulceration, which was sutured until the bleeding stops. The next procedure we perform is anterior wall gastrotomy, after which we find posterior wall ulcer fistula, communicating with pancreatic pseudo cyst $2 \times 5 \mathrm{~cm}$ large. Because of the critical patient's condition the cyst was drained throughout lineal flexure of the descend mesocolon, finishing with one level gastrotomy suture and two levels gastric fistila suture.

\section{DISCUSSION}

The pancreatic pseudo cysts are often complication of the acute (7-15\%) and chronic pancreatitis (в 20-25\%) $(1,2)$.

Table. 1. Causes of hemorrhagic complications in chronic pancreatitis (by Ammori)

(A) Pancreatitis-related

1. Pseudoaneurysms or arterial wall necrosis and rupture.

2. Gastric \pm oesophageal varices (splenic vein thrombosis with left-sided portal hypertension).

3. Intracystic haemorrhage from vessels within the pseudocyst wall.

4. Splenic rupture.

(B) Coexistent pathology

1. Peptic ulceration.

2. Gastritis, duodenitis, or stress ulceration.

3. Oesophageal varices (alcoholic liver disease with portal hypertension).

4. Mallory-Weiss tears.

The persisting pseudo cysts may lead to different serious 
complications, including infection, abscess formation, bleeding by arosing nearby blood vessels. (Tabl.1).

A result of the peripancreatic vessels arosion in the pseudo cystic cavity is the pseudo aneurism formation $(5,7)$. Pseudo aneurisms are been found in 5- 8\% of the cases of chronic pancreatitis. The reason of the formation is the enzyme assimilation of the close vessel wall. The most frequently affected are the lienal and gastroduodenal arteries. The pancreatic pseudo aneurism rupture in the lumen of the digestive tract very often is difficult to diagnose because of the massive bleeding and the source is difficult to be found by endoscopic investigation. The correct diagnose submitting results from on time conducted CT-scan and selective angiography if possible (4). The treatment is surgical and results from the patients' general condition and the intraoperative findings - from surgical hemostasis by suturing or ligation of the bleeding vessel to left or right hemipancreatectomy, splenectomy or partial gastric resection (7). Ussualy there is tight postoperative period with possible different complications. There are high postoperative morbidity and mortality with tendency of lowering from 14,3 to $4,5 \%$, letality from 28,6 to $5,6 \%$ (1).

\section{CONCLUSIONS}

1. The compicated pancreatic pseudo cysts are rear but serious complication requiring immediate surgical treatment.

2. The surgical treatment must be conducted in highly specialized and equipped medical institutions.

3. The operative behavior is defined by the patient's condition and the intraoperative findings.

\section{REFERENCES}

1. Brouquet, J. Lefevre, B. Terris, S. Silvera, B. Randone, O. Soubrane, O. Scatton, A pancreatic pseudocyst associated with three simultaneous hemorragic complications, Journal de Chirurgie Vol 144, 4 - juillet-août, 2007, 336-338

2. Cucu A, Cornila R, Cristian A, Durach L, Sculeanu R. Pancreatic pseudo-cyst, Chirurgia (Bucur). 2003 Jul-Aug;98(4):337-40

3. Gostishchev VK, Afanas'ev AN, Ustimenko AV., Diagnosis and treatment of complicated postnecrotic cysts of pancreas, Khirurgiia (Mosk), 2006;(6):4-7.

4. Yin WY., The role of surgery in pancreatic pseudocyst. Hepatogastroenterology. 2005 Jul-Aug; 52(64):1266-73

5. Nemeş R, Georgescu I, Mârgâritescu D, Sâftoiu A, Chiutu L, Georgescu E, Surlin V, Cârtu D, Dumitrescu D, The pancreatic pseudocyst - late complication of the severe acute pancreatitis. Therapeutic options, Chirurgia (Bucur). 2006 May-Jun;101(3):259-65.

6. Urakami A, Tsunoda T, Kubozoe T, Takeo T, Yamashita K, Imai H.,Rupture of a bleeding pancreatic pseudocyst into the stomach, $J$ Hepatobiliary Pancreat Surg. 2002;9(3):383-5.

7. Zhou F, Wang C, Xiong J, Wan C, Zheng C, Experience in diagnosis and treatment of bleeding complications in severe acute pancreatitis by TAE. $J$ Huazhong Univ Sci Technolog Med Sci. 2005;25(2):182-4 